\title{
A fronteira transnacional do grande sertão rosiano
}

Marli Fantini Scarpelli*

* Professora do Departamento de Semiótica e Teoria da Literatura - Faculdade de L etras/UFMG. 
Guimarães Rosa é um viajante e sua poética tem vocação plurilingüística, intercultural e transnacional. O conhecimento de vários idiomas, o trânsito por inúmeras culturas, a diversidade de focos assegurada pelo olhar multifacetado do escritor - sertanejo, médico, intelectual, diplomata, Chefe do Serviço de Demarcação de Fronteiras - são, no meu entendimento, fatores decisivos na constituição de sua poética de "fronteiras". O feixe de produções tanto ficcionais quanto documentais do escritor possui uma abrangência tal que possibilita a seus leitores e críticos, além de interpretar os limites intrínsecos de sua linguagem literária, apreender e traduzir as relações metafóricas que o entorno sócio-político-cultural do seu campo discursivo irá deflagrar.

$\mathrm{Na}$ vasta territorialidade do grande sertão rosiano, mesclam-se várias temporalidades a partir de cuja superposição emerge toda uma gama de vozes dissonantes. O convívio tensionado entre vários pólos dicotômicos se materializa sobretudo na "terceira margem", emblemática imagem rosiana que dá visibilidade a entre-lugares fronteiriços onde surge a oportunidade de intercâmbio entre categorias via de regra polarizadas. B em e mal, centro e periferia, razão e intuição, arcaico e moderno, distintas leituras de mundo, com o imbricamento e a superposição de línguas contrabandeadas de formações culturais de diferenciadas procedências desfilam na espacialidade migrante que Guimarães Rosa concebe para representar o modo de formação híbrida do Brasil e da América Latina. É dessa forma que, em sua resposta ao modelo impositivo da "metrópole", Rosa contribui para a valorização da heterogeneidade cultural que permeia o regionalismo transnacional praticado em sua literatura e na de outros escritores latinoamericanos afinados com a mesma tendência. 
A apropriação criativa às vanguardas européias e seu desdobramento nas técnicas renovadoras do regionalismo transnacional, cujo aproveitamento na obra de autores continentais, como J osé Maria Arguedas, J uan Rulfo, Gabriel Garcia Márquez e J oão Guimarães R osa, institui, segundo Antonio Candido, ${ }^{1}$ um modelo comum às literaturas desses escritores. Marcando diferença em relação a modelos importados ou impostos pelo processo de "transplante cultural" a que o B rasil em particular e a América L atina como um todo se viram submetidos durante vários séculos de "aculturação", o regionalismo transnacional inaugura, no continente, um novo espaço discursivo. Para abordá-lo, torna-se necessária a perspectiva comparatista, que poderá, a partir de agora, "assumir o papel que lhe cabe num país caracterizado pelo cruzamento intenso de culturas, como é o Brasil". ${ }^{2}$

Dada a pluralidade de discursos críticos e de dispositivos teóricos desenvolvidos pelo comparatismo literário inter-americano, sobretudo na perspectiva dos Estudos Culturais, penso que seria inconseqüente uma abordagem contemporânea de quaisquer obras literárias continentais, desvinculada das condições simbólicas em que elas foram geradas. É dessa perspectiva que pretendo enfocar o Guimarães R osa-narrador, agente de um discurso alternativo, que deixa vazar, em seu campo discursivo, a imagem de um escritor preocupado com uma causa de ordem sócio-político-cultural. Dessa forma, a conjunção do comparativismo latino e iberoamericano com as produções concretas das "literaturas alternativas" contribui para se compreender mel hor o locus de en unciação a partir do qual formações discursivas produzidas em situação de subalternidade podem enunciar e denunciar as condições de opressão e recalcamento que lhe foram impostas pelo legado colonial.

A diversidade da obra rosiana e o locus que define suas condições de enunciação - zonas fronteiriças assinaladas pela hibridez e pela "heterogeneidade multitemporal" ${ }^{3}$, segundo expressão de Canclini ${ }^{4}$ - solicita uma abordagem comparativista que, tendo como eixo o interculturalismo, possibilita repensar conceitos como "nacionalismo", "nação", "pátria", "relações identitárias". Não se pode, ademais, perder de vista de que, ao inter-relacionar-se com vários campos de conhecimento, a literatura de R osa, além de rasurar seus próprios limites, dramatiza a relação intersubjetiva entre história e estória, realidade e ficção, autoria e atoria, instituindo, dessa forma, novos paradigmas relacionais que possibilitam, no atual contexto de globalização, multiculturalismo e suas demandas de flexibilização de fronteiras políticas e culturais, novas alternativas para ler e habitar o mundo.

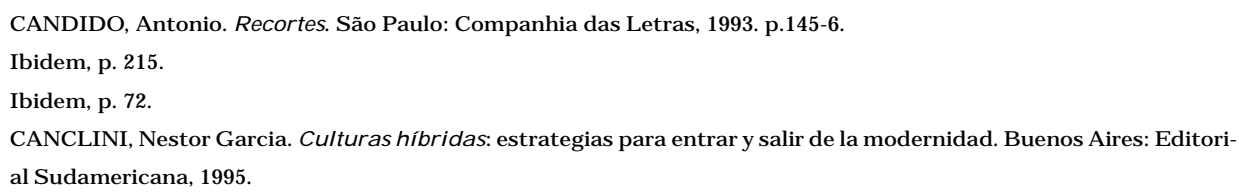




\section{Transitividade Cultural}

O princípio de "transitividade cultural"5 com que R osa e personagens rosianas operam provém, em grande parte, do trânsito realizado pelo escritor entre o sertão e o mundo, entre sua matriz lingüística de base regional e os vários idiomas que ele vem a dominar. A conjunção entre idiomas - cada um dos quais trazendo, em sua própria singularidade, os traços de sua cultura - irá contribuir para a descristalização dos localismos reducionistas fixados pela acentuada cor local característica das manifestações regionalistas, que anteciparam o desafio rosiano em criar um novo espaço de transitividade territorial e cultural na literatura regionalista praticada, principalmente entre as década de 30 e 50, no Brasil e na América Latina.

A partir do intercâmbio entre línguas e culturas, a literatura de Guimarães Rosa situa o local em um âmbito transnacional, fazendo emergir um espaço de transitividade polifônica e plasticidade cultural que integra e superpõe "imaginários e produtores culturais de vertentes diversas". ${ }^{6}$ Com base nas reflexões de Ángel R ama, M abel M oraña anota a significativa intervenção desses escritores na forma como a América Latina vem se inscrevendo no projeto de modernização ocidental. E ndossando a afirmativa de R ama, segundo o qual a modernidade constituiu, na América latina, a fronteira onde se puderam conectar áreas culturais, pensamentos e projetos muito diversos, ela identifica, no espaço heterogêneo do continente, uma zona de trocas, empréstimos e negociações. ${ }^{7}$

A inserção de outros idiomas no português é um dos procedimentos que permitem a Guimarães R osa quebrar os parâmetros particularistas de língua. Diferentemente da utópica originalidade isolacionista com que, desde o romantismo, o regionalismo patriótico e provinciano vinha-se protegendo contra as influências externas e sobretudo contra a dependência cultural, o escritor mineiro põe sua região em relação de interatividade com outras paragens continentais e universais. Antonio Candido considera que, dos três momentos de manifestação regionalista continental por ele examinados, somente a terceira vertente - consolidada por escritores como J osé M aría Arguedas, G abriel García Márquez, Augusto R oa Bastos e J oão Guimarães Rosa - cria alternativas inovadoras, permitindo-lhe escapar ao anacronismo e ao provincianismo a que ficaram sujeitas as vertentes anteriores. Ao se fixar nas formas mais peculiares da realidade local, em lugar de afirmar a identidade nacional, como pretendia, o regionalismo romântico e o naturalista acabam

\footnotetext{
Sobre "transitividade cultural", ver MORAÑA. Ángel Rama y los estudios lati noamericanos. Pittsburg: Inst. Intern. de Literatura I beroamericana, 1997. I deologia de la transculturación. p. 17-8.

Ibidem, p. 11.

Ibidem, p. 10.
} 
oferecendo à sensibilidade européia o exotismo que ela desejava, o que, segundo Candido, se torna uma "forma aguda de dependência na independência". ${ }^{8}$

A permeabilização da matriz regional, realizada sob o influxo da transitividade territorial, lingüística e cultural, possibilita a R osa adotar a combinatória de práticas culturais representativas da índole conflitiva e desafiante com que a América L atina se insere na modernidade ocidental. Dessa forma, sua obra ultrapassa os limites do subdesenvolvimento continental que levaram Candido a refletir que “nossas literaturas latino-americanas, como também as da América do Norte, são basicamente galhos das metropolitanas". ${ }^{9}$ Ainda que semeados no quintal terceiromundista, os germens dessa literatura voltada para o ano 2000 proliferam e, sobretudo a partir de Rosa, já dão frutos no jardim das musas.

\section{Transculturação narrativa}

Tanto o procedimento tradutório quanto o transculturador fornecem a Guimarães R osa o instrumental necessário para reler a própria aprendizagem de "memória coletiva", cujo maior "monumento", no mundo destituído de escrita e de patrimônio arquitetônico, é a narrativa oral que mantém forte parentesco com as lendas e os mitos. R enovar a palavra narrativa, mediante o concurso de outros códigos e com a mediação de outras formações discursivas é uma forma por meio da qual o escritor pode preservar a cultura cuja sobrevivência histórica depende dessa palavra.

Nas sociedades sem escrita, arquivos ou monumentos, cabe aos especialistas em memória - os "homens-memória" - a função de depositários da "memória coletiva". Eles são a "memória dessas sociedades", guardiães da tradição em que a história e o mito normalmente se confundem. ${ }^{10}$ Sob a perspectiva de um estrangeiro-tradutor, Guimarães Rosa, depois de diversas viagens ao exterior, retorna ao interior de $M$ inas, para recuperar os vestígios de formações culturais arcaicas debilmente preservadas pela tradição oral. Ato simbólico, por excelência, a fundação é uma construção social e, portanto, um ato de cultura. R ecuperar a oralidade através da escritura é, no entendimento de Ana Pizarro, um ato fundacional que cumpre, na perspectiva contemporânea, uma função simbólica de caráter restaurador, que se aproxima à da fundação das cidades. ${ }^{11}$

8 CANDIDO. A educação pela noite e outros ensai os. São Paulo: Ática, 1989. A nova narrativa. Literatura e subdesenvolvimento. p. 157 e passim.

Ibidem, p. 151.

10 LE GOF, J acques. História e memória. Trad. Irene Ferreira, Bernardo Leitão, Suzana F. Borges. Campinas: Ed. da Unicamp, 1996. p. 428-9.

11 PIZARRO (Org.) . América Latina: palavra, literatura e cultura. São Paulo: Memorial/Campinas: Unicamp, 1993. p. 26. 
Ángel Rama discorre sobre a prática transculturadora de escritores latinoamericanos provenientes de regiões que, ao adotarem práticas autônomas e endogâmicas, isolaram-se do processo de modernização ocidental. ${ }^{12}$ Situados "entre duas águas", esses escritores, a exemplo de G uimarães R osa, oriundo de M inas G erais; G arcía M árquez, da costa colombiana; J uan R ulfo, de J alisco, lograram, através de sua literatura, permeabilizar a passagem do arcaico para o moderno, da esfera regional para a transnacional. Ao se integrarem a centros urbanos, esses escritores puderam absorver novas influências, sem contudo perder as marcas profundas de sua cultura regional. E m outras palavras, eles puderam, via literatura, estender uma ponte entre setores localistas com padrões culturais próprios ( freqüentemente muito arcaicos) e um projeto modernizador de maior amplitude.

Uma das tarefas do transculturador é desafiar a cultura estática, presa à tradição local a desenvolver suas potencialidades e produzir novos significados sem, contudo, perder sua textura íntima. Instuído entre os pólos da resistência tradicionalista e do impulso modernizador, o processo da transculturação se concretiza em dois grupos básicos de personagens. No primeiro pólo, o da resistência, encontram-se personagens representativas da região, enraizadas ao local e defensoras de suas tradições. No segundo pólo, situa-se o narrador (também ele uma personagem) ou um elemento externo à obra, geralmente identificado ao destinatário a quem é dirigida a narração. Um e outro são depositários de um legado cultural, e sua tarefa é fazer a mediação entre o enraizamento da tradição regional e a modernização da cultura nacional. ${ }^{13}$

Para Rama, Riobaldo, narrador-protagonista de Grande sertão: veredas, ${ }^{14}$ cumpre exemplarmente a função transculturadora. De fato, pode-se observar que, além de ocupar o entre-lugar entre distintas culturas, fazer um pacto ficcional com um interlocutor que, diferentemente dele, identifica-se com normas urbanas e um saber formal, o ex-jagunço se coloca entre bandos antagônicos, entre três amores, entre as águas de dois rios, entre Deus e o demo, e seu relato, ao se segmentar em duas partes, duplica a narrativa do romance, reproduzindo e reafirmando, em sua própria estruturação, o processo de transitividade operado pelo narrador na esfera discursiva.

A mparado pelo princípio de "plasticidade cultural", R iobaldo assegura o próprio trânsito entre os distintos planos que se ocupará em mediar. Para tanto, é-Ihe fundamental manter-se numa posição independente ou, no mínimo, distanciada em relação aos diversos sistemas culturais com que se vê confrontado, à alta hie-

\footnotetext{
RAM A, Ángel. Transculturación narrativa en América Latina. Montevideo: Arca Editorial, 1989. p. 95-6. Ibidem, p. 99-100.

ROSA, J oão Guimarães. Grande sertão: veredas. Rio de J aneiro: N ova F ronteira, 1984. Doravante, este romance será citado mediante a sigla GSV, seguida da respectiva numeração.
} 
rarquia rural, aos distintos chefes jagunços aos quais ele ora se associa, ora se dissocia: “Eu, quem é que eu era? De que lado eu era? Zé B ebelo ou J oca R amiro? Titão Passos... o Reinaldo... De ninguém eu era. Eu era de mim. Eu, Riobaldo" (GSV, 141).

\section{Fronteira transnacional}

Da amplitude heterotópica do romance Grande sertão: veredas emerge um espaço híbrido e disjuntivo onde convivem várias alteridades e distintos planos temporais. Trata-se do "Curralinho" - topos fronteiriço entre a arcaica tradição regional e a modernidade urbana - para onde se muda o protagonista, quando jovem, com o intuito de estudar "as primeiras letras" e de onde foge da ascendência paterna para realizar suas várias "travessias". O significante "Curralinho" sugere a linha limítrofe entre regiões e, ao mesmo tempo, um concentrado campo de tensões onde se superpõem, convivem e se inter-relacionam várias expressões de alteridade. I magem de uma fronteira transnacional, plurilingüística e intercultural, esse cenário é atravessado pelo entrecruzamento de inúmeras vozes dissonantes e dialógicas a reverberar na heterogeneidade contraditória das variações polifônicas.

Marcada pela hibridez e pela heterogeneidade conflitiva, a formação discursiva dessa passagem recusa a restrição da singularidade e do local, situando o problema num âmbito suficientemente amplo para abranger questões contemporâneas, extremamente contraditórias, que dizem respeito, ao mesmo tempo, à globalização e ao retorno às culturas locais; às diversas formas de hibridez decorrentes dos encontros de diásporicos às margens das nações e, em simultâneo, o acirramento de sentimentos étnicos e identitários.

Espaço permeável a interações e mudanças, o "Curralinho" abriga basicamente dois grupos. O primeiro, remanescente da tradição local, constitui-se de setores da hierarquia rural e seus aparatos ideológicos - capatazes e jagunços, força de trabalho semi-escrava. Em sua luta para preservar a própria hegemonia político-econômica, esse grupo transforma a zona fronteiriça em um grande campo de batalha, onde - sob a proteção de sanguinolentos bandos jagunços - ele se arma em defesa de sua tradição, família e propriedade. Os jagunços, por seu turno, incumbidos de proteger e mapear os grandes feudos, travam, entre si, intestinas e encaniçadas lutas, numa constante e estreita divisão de poder, sem que eles próprios, malgrado seu poder de fogo, usufruam das posses e da integridade de latifundiários como seo Ornelas, seo Habão, seo Selorico M endes. O processo de reificação a que os jagunços são submetidos é percebido pelo "chefe" Zé B ebelo que o explicita a Riobaldo: "Só eu... ou você mesmo, Tatarana. M as a gente somos garrotes remarcados" (GSV, 398). E sse processo é ainda registrado pelo protago- 
nista do romance, que se reconhece na mesma situação degradada que a dos demais jagunços. Como estes, aquele não passa de "fulão e sicrão e beltrão e romão - pessoal ordinário" (GSV, 58).

"Padrinho" de Riobaldo, Selorico Mendes assevera ao "afilhado" que "cada lugar é só de um grande senhor, com sua família geral, seus jagunços mil, ordeiros" (GSV, 104). E ssa fala é significativa por confirmar que os próprios donos das terras e seus "filhos" têm a consciência de que seu poder de fogo possui a eficácia de bloquear o curso de mudanças sócio-culturais e históricas. A visita do poderoso chefe J oca R amiro com toda sua entourage à fazenda São G regório, de Selorico M endes, salienta o estreito comprometimento deste com a alta hierarquia jagunça. Introduzir R iobaldo no manejo de armas é a forma como o latifundiário institui laços com o filho "ilegítimo" e o prepara para ocupar seu lugar no latifúndio. É, portanto, sob o signo da beligerância, que R iobald o se insere nessa arcaica tradição rural, cuja "malignidade", numa reviravolta performática, ele próprio tratará, mais tarde, de combater.

Queria que eu aprendesse a atirar bem, e manejar porrete e faca. Me deu logo um punhal, me deu uma garrucha e uma granadeira. Mais tarde, me deu até um facão enterçado, que tinha mandado forjar para próprio, quase do tamanho de espada e em formato de folha de gravatá" (GSV,105).

À falta de outras habilidades do filho, o pai decide também que ele estude, designando o M estre Lucas, do Curralinho, para ensinar-Ihe as primeiras letras:

"Baldo, você carecia mesmo de estudar e tirar carta-de-doutor, porque para cuidar do trivial você jeito não tem" (GSV,106).

É, portanto, em nome do pai, que Riobaldo será o "Cerzidor", certeiro nos tiros e nas palavras. Inseguro no uso de outras armas, ele tem, contudo, a segurança de manejar estas duas, por meio das quais se prepara para ocupar e desocupar o lugar do pai.

Por seu turno, o segundo grupo, sendo desenraizado e, portanto, desvinculado das tradições locais, pode ser associado à itinerância, ao nomadismo, à fluidez identitária. Trata-se de mascates, comerciantes, imigrantes, frontiers, borders, que, em face de sua própria indefinição sócio-cultural, ajusta-se ao espírito de renovação da modernidade, polarizando-se, nesse sentido, às formas de resistências assumidas pelo primeiro grupo. Assim, enquanto a oligarquia rural se recusa à mobilidade, fixando-se beligerantemente nos valores locais, o outro grupo se contorciona para manejar - com um mínimo de perdas - o comércio simbólico que lhe possibilite realizar novas formas de interatividade com a cultura local. 
Por não estar enraizado em nenhuma tradição nem se identificar a nenhuma facção jagunça, R iobaldo pode colocar-se em posição transitiva e realizar a mediação entre os dois sistemas culturais. É , portanto, a partir desse espaço de interação e conflitividade, que ele irá permeabilizar o convívio entre várias temporalidades superpostas - "o tempo no tempo" (GSV, 321), conforme expressão dele -, de distintas culturas e de diferentes sistemas lingüísticos, fazendo do sertão o espaço metafórico de transição entre o arcaico e o moderno, o regional e o universal.

Dessa forma, Riobaldo aprende as "primeiras letras" sob várias mediações, na fronteira intersticial assinalada pela plasticidade sócio-cultural, pelo plurilingüismo e pela heterogeneidade multitemporal. O Curralinho é, por conseguinte, o entre-lugar propício para a deflagração dos processos de deslocamento e travessia do narrador de Grande sertão: veredas. Mas, sobretudo, espaço de mediação entre a fixidez da cultura local e as singularidades dissonantes de culturas estrangeiras, a exemplo do convívio entre o narrador-transculturador com seo Assis Wababa (comerciante turco, cuja "linguagem garganteada" exerce forte atração sobre Riobaldo (GSV, 107) e com o alemão Vupes, seo E mílio Wusp, um mascate ocupado com trocas comerciais, lingüísticas e culturais nas suas idas e vindas entre o mundo rural e o mundo urbano (GSV, 116).

Ao descrever as mudanças sofridas pelo alemão Vupes, o narrador chama a atenção para o progressivo processo de assentamento desse imigrante em território alheio, em similitude com a adaptação sócio-cultural já efetivada anteriormente pelo turco Wababa. No relato dos sucessivos momentos de adaptação do mascate, é possível vislumbrar, nas formas concretas em que se efetivam as trocas culturais entre o meio rural e o urbano, o prenúncio do ingresso do sertão na modernidade.

Para traduzir a pluralidade de formações discursivas que emergem da coexistência de diferentes tradições, línguas, culturas e temporalidades, o narrador transculturador de Grande sertão: veredas opera um procedimento que Walter Mignolo (Apud. Pizarro,1993) classifica como "hermenêutica heterotópica", paradigma mediante o qual se pode compreender o modo como os membros de cada cultura pensam as práticas culturais e discursivas do outro. ${ }^{15}$ No trecho abaixo, ilustrativo desse paradigma, o narrador acompanha e traduz o processo de transitividade cultural do imigrante alemão:

Pois ia me esquecendo: o Vupes! [...] Esse um era estranja, alemão, o senhor sabe: clareado, constituído forte, com os olhos azuis, esporte de alto, leandrado, rosalgar - indivíduo mesmo. Pessoa boa. Homem sistemático, salutar na alegria séria. Hê, hê, com toda a confusão de política e brigas, por aí, e ele não

15 MIGNOLO, Walter. Palabras pronunciadas con el corazón caliente: teorias del habla, del discurso y de escritura. In: PIZARRO, Ana (org.), cit. p. 531. 
somava com nenhuma coisa: viajava sensato, e ia desempenhando seu negócio dele no sertão - que era de trazer e vender de tudo para os fazendeiros: arados, enxadas, debulhadora, facão de aço, ferramentas rógers e roscofes [...]. Diz-se que vive até hoje, mas abastado na capital - e que é dono de venda grande, loja, conforme prosperou. (GSV, 66).

Entre a estabilidade do comerciante turco e o gradativo ajustamento do mascate alemão ao local da cultura, pode-se perceber o trânsito que antecipa a adaptação e a hibridização cultural e idiomática de imigrantes em geral e, por analogia, o processo de transculturação tematizado ao longo do romance. À medida que se materializa no romance, esse processo dá visibilidade às trocas simbólicas nele representadas. O afã de criar um máximo divisor comum para línguas estrangeiras entre si leva o narrador de Grande sertão: veredas - a partir da própria perspectiva cultural e lingüística já heterotópica - a operar como tradutor e transculturador de sistemas excludentes. A lém de se ressaltar a coexistência entre alteridades, que ganham lúdica visibilidade no paradoxo "alegria séria", o trecho supra citado sobreleva a mescla idiomática impressa nas palavras rógers e roscofe, signos do comércio simbólico realizado pelo "mascate" estrangeiro.

\section{Trocas culturais}

Em Grande sertão: veredas, o processo de transculturação efetuado pelo narrador realiza-se através da mediação de um interlocutor culto e cosmopolita que ouve daquele (um fazendeiro, quase barranqueiro, no presente; e ex-chefe de jagunçagem, no passado) notícias das transformações sofridas pelo sertão. O processo de transitividade histórico-cultural engloba, desde a arcaica e truculenta ordem regional, emblematizada por truculentas guerras jagunças, até chegar à atualidade do relato, que é contemporâneo ao ingresso do sertão na modernidade urbana. Surpreendido pela consciência "etnológica" do narrador, esse contraditório processo de modernização - posto que ainda incipiente - já traz, em seu bojo, o lado perverso do progresso:

Mas, o senhor sério tenciona devassar a raso este mar de territórios, para sortimento de conferir o que existe? Tem seus motivos. Agora - digo por mim - o senhor vem, veio tarde. Tempos foram, os costumes demudaram. Quase que, de legítimo leal, pouco sobra, nem não sobra mais nada. Os bandos bons de valentões repartiram seu fim; muito que foi jagunço por aí pena, pede esmola. M esmo os vaqueiros duvidam de vir no comércio vestidos de roupa inteira de couro, acham que o traje de gibão é feio e capiau. E até o gado no grameal vai minguan- 
do menos bravo, mais educado [...] Sempre nos gerais, é à pobreza, à tristeza. U ma tristeza que até alegra (GSV, 24).

P rivilegiado locus de enunciação e de trocas simbólicas, a fronteira intercultural onde R iobald o se localiza (seja inicialmente para transitar, seja posteriormente para enunciar) possibilita surpreender, de forma concentrada, as formações discursivas denotadoras de distintas temporalidades e culturas. Dessa forma, é possível examinar o processo de mesclagem entre urbes culturais desconectadas - o interiorregional e o exterior-universal - e, como conseqüência, surpreender as transformações lingüísticas, manifestas nos fenômenos de hibridização sintática e de acomodação gráfico-fonética entre o alemão e o português e, por analogia, entre este e outros idiomas. $\mathrm{Na}$ passagem abaixo, a exemplo de uma prática recorrente no romance, $\mathrm{R}$ iobaldo agencia a transculturação idiomática, cujo resultado, como se pode verificar, é a heterogeneidade cultural e semiótica:

E como é mesmo que o senhor fraseia? Wusp? É. Seo Emílio Wuspes... Wúpsis... Vupses. Pois esse Vupes apareceu lá, logo me reconheceu, como me conhecia, do Curralinho. Me reconheceu devagar, exatão. Sujeito escovado! M e olhou, me disse: — «Folgo. Senhor estar bom? Folgo...»E eu gostei daquela saudação [...] - «Seo Vupes, eu também folgo. Senhor também estar bom? Folgo...»-que eu respondi, civilizadamente (GSV, 66).

É num contexto fecundo para a prática da diglosia ${ }^{16}$ - o entre-lugar híbrido e multifacetado do "Curralinho", onde se confrontam e se inter-relacionam várias alteridades, línguas, temporalidades e distintas formações culturais - que R iobaldo irá aprender as "primeiras letras": "Soletrei, anos e meio, meante cartilha, memória e palmatória. Tive M estre Lucas, no Curralinho, decorei gramática, as operações, regra-de-três, até geografia e estud o pátrio. E m folhas grandes de papel, com capricho desenhei bonitos mapas" (GSV, 14). A opção riobaldiana pelo convívio com diferentes sistemas culturais e lingüísticos confirma-se nesta afirmativa: “Toda a vida gostei demais de estrangeiros" (GSV, 107). É sintomático, nesse sentido, que o "Curralinho" - zona fronteiriça entre o nacional e o estrangeiro, a vida familiar do narrador e sua vida coletiva em meio a forasteiros e bandos jagunços - represente o espaço de transição a partir do qual ele, como um filho pródigo, se exila da casa paterna para, a partir da diápora, realizar sua missão transculturadora.

Tão certeiro no manejo das armas quanto das palavras, o jagunço-letrado usa as primeiras para mirar, com seus implacáveis tiros, o "escuro" da malignidadejagunça.

16 A "diglosia" - prática específica e assimétrica do bilingüismo e situação típica em contextos coloniais - "remete à coexistência, no seio de uma formação social, de duas normas lingüísticas de prestígio social desigual". LIENHARD. Asedios a la heterogeneidad cultural: libro de homenaje a Antonio Cornejo Polar, p. 71. T radução minha. 
As segundas serão usadas tanto para cerzir os rombos que ele próprio abriu, instituindo, dessa forma, uma nova rede de sentidos. Assim, do entre-lugar do Curralinho, o jagunço-letrado se apropria das "letras" e das "armas" que lhe foram legadas pelo pai para combater o sistema que este representa, numa evidente metáfora à dependência colonial que deve ser combatida a partir da apropriação ladina e insurgente dos próprios aparatos bélicos e ideológicos da política colonizadora.

Encarnação da cólera e das virtudes guerreiras, Riobaldo é alçado ao mais alto patamar da hierarquia jagunça quando, depois de seu pacto "simbólico" com o demo ${ }^{17}$, torna-se o beligerante chefe "Urutu-B ranco". ${ }^{18}$ É sob a proteção desse "escudo" que ele cumpre sua tarefa heróica: modernizar o sertão, mediante o combate ao mal da jagunçagem. Em homologia com outros transculturadores, esse herói da modernidade periférica - frente ao desafio de questionar, desalinhavar e recosturar os fundamentos da identidade histórica e cultural de sua região - não poupa meios para permeabilizar as fronteiras que isolavam o seu arcaico mundo sertanejo da modernidade urbana. O princípio da "plasticidade cultural", adotado pelo "Cerzidor", abre as porteiras do "Curralinho" para o contrabando de línguas e culturas franqueadas na nova fronteira que se abre, no fim do século do colonialismo, à literatura latino-americana, a qual, segundo G uimarães R osa em sua entrevista a G unter L orenz em 1965, inicia agora seu futuro. Um futuro que sanciona ao continente um desempenho mais efetivo no comércio simbólico implicado nas crescentes trocas multiculturais, conforme prenuncia a passagem abaixo:

Estou firmemente convencido, e por isso estou aqui falando com você, de que no ano 2000 a literatura mundial estará orientada para a América Latina; o papel que um dia desempenharam Berlim, Paris, Madrid ou Roma, também Petersburgo ou Viena, será desempenhado pelo Rio, B ahia, B uenos Aires e M éxico. O século do colonialismo terminou definitivamente. A América Latina inicia agora o seu futuro. Acredito que será um futuro muito mais interessante, e espero que seja um futuro humano. ${ }^{19}$

17 Penso que o grande pacto ocorrido no romance Grande sertão: veredas é um pacto ficcional entabulado não apenas com o narratário de $\mathrm{R}$ iobaldo, mas também com outras vozes, desafiadas a interagirem na múltiplice rede de trocas simbólicas propostas pela escrita rosiana.

18 "Urutu-B ranco" é um dos epítetos do "herói" R iobaldo (os outros dois são "Cerzidor" e "Tatarana"). Sobre atributos e nomes guerreiros do protagonista de Grande sertão: veredas, bem como seu parentesco com personagens da "Cavalaria" ("avatar sertanejo da Cavalaria" e respectivamente "Don R iobaldo, cavaleiro dos campos gerais"), ver CANDIDO, Antonio. Tese e antítese: ensaios. O homem dos avessos. São Paulo: Ed. Nacional, 1964. p. 129; e PR OENÇA, Manuel Cavalcanti. Trilhas do Grande Sertão. Rio de J aneiro: Serv. Docum. do MEC, 1958. p. 33 (Cadernos de Cultura, 114). ROSA . Gui marães Rosa: ficção completa.Diálogo com G uimarães. R osa R io de J aneiro: Nova A guilar, 1994 , v. I, p. 61. 